\title{
SOBREIMPRESIONES CARTOGRÁFICAS Y FUGAS TEXTUALES: POLÍTICAS DEL ESPACIO A PARTIR DEL POEMA «LOS NEOCHILENOS» DE ROBERTO BOLAÑO*
}

\author{
Cristóbal Vergara-Espinoza**
}

\section{Resumen}

El presente trabajo propone una lectura del poema «Los Neochilenos» de Roberto Bolaño, que argumenta a favor de su papel central en la configuración de los espacios diseñados por el autor. Mediante un diálogo entre este poema y el resto de la obra de Bolaño se sostiene que el autor ofrece una interpretación de las fronteras como espacios de intercambio entre las zonas interiores y exteriores, resignificando el motivo del viaje como un tránsito que subvierte las fronteras políticas y tensiona el arraigo territorial de los diversos cánones inscritos en los espacios nacionales. De esta forma, los desplazamientos realizados por los personajes de Bolaño describirían trayectos que permiten articular espacios de confluencia entre el Mapa y la Biblioteca, discursos que confluyen en la configuración de las identidades nacionales.

Palabras clave: Roberto Bolaño, «Los neochilenos», margen, canon, frontera, biblioteca, nación.

\section{CARTOGRAPHIC OVERPRINTS AND TEXTUAL FUGUE: SPACE POLITICS FRON THE POEM «LOS NEOCHILENOS» BY ROBERTO BOLAÑOS}

\begin{abstract}
This paper proposes a reading of the poem «Los Neochilenos» by Roberto Bolaño, arguing for their central role in the configuration of the spaces designed by the author. Through a dialogue between this poem and the rest of the work of Bolaño it is argued that this author offers an interpretation of borders as spaces of exchange between interior and exterior zones, giving a new meaning to the theme of travel as a transit that subverts political borders and it puts in dialogue the various registered canons in national spaces. Thus, the trips made by Bolaño's characters describe paths which allow joint spaces of convergence between the Map and the Library as instances of power.
\end{abstract}

Keywords: Roberto Bolaño, «Los neochilenos», margin, canon, border, library, nation.

* Este trabajo es el resultado del seminario de Teoría Literaria del Doctorado en Literatura Hispanoamericana Contemporánea de la Universidad de Playa Ancha, impartido por la Dra. Sofía Fernanda Moraga-García.

** Chileno. Profesor de castellano y Licenciado en Educación. Egresado de Magíster en Literatura Chilena e Hispanoamericana. Estudiante del Doctorado en Literatura Hispanoamericana Contemporánea de la Universidad de Playa Ancha, Valparaíso, Chile. profesorcristobalv@gmail.com 


\section{Mapas desbordados, bibliotecas asaltadas: a modo de introducción}

La escritura de Roberto Bolaño (1953-2003) constituye una propuesta de movimiento. Ello refiere una dinámica de desplazamientos múltiples que permiten al autor configurar diversos espacios de tránsito sobre los que sus personajes realizan trazados problemáticos. Primero, están los tránsitos textuales: éstos refieren la dinámica de referencias intra e intertextuales que brindan a la obra del autor de Tres (2007) una apariencia rizomática, un sistema de multiplicidades que prolifera a partir de la auto-mención (Candia 193) y de la mención de otros sistemas, la obra de otros, entablando intercambios que enriquecen y complejizan el universo que delinean ${ }^{1}$. Y también están los tránsitos espaciales: son los constantes viajes de sus personajes, sujetos en fuga que por medio del nomadismo subvierten las fronteras nacionales para configurar un espacio amplísimo, cuyas coordenadas principales serían México, España y Chile.

De lo anterior se desprende que el mapa de Bolaño entra en disputa con el mapa político que determina las fronteras nacionales sobre las que se extiende su universo. Su escritura, por tanto, antes que someterse a un discurso de poder que estría la geografía y coopera con la instauración de relatos nacionales, propone una cartografía que se extiende sobre aquel mapa para abrir espacios de comunicación internacional y proponer fisuras de unas fronteras entendidas como espacios de intercambio. Esto se lleva a cabo no solo a través del motivo del viaje, central en su producción y resignificado por medio de una estrategia que permite articular un devenir diaspórico, sino también mediante la configuración de un espacio de lectura/escritura que le permite al autor transitar por diversos registros escriturales centrales y marginales, nacionales e internacionales, un canon propio que busca problematizar las diversas jerarquías literarias que se enquistan en el campo cultural hispanohablante.

De esta forma, la escritura de Roberto Bolaño establece una compleja relación con dos instancias de poder centrales en la reflexión que motiva

Para una mayor profundización en esta idea, consultar el artículo de Candia, Alexis «Tejidos transparentes y lineas de fuga en la literatura de Roberto Bolaño». Anales de literatura chilena, no. 21, 2014, $179-198$. 
este ensayo: la Biblioteca y el Mapa. No obstante lo anterior, es preciso dejar en claro que la apuesta de Bolaño no busca anarquizar estas agencias. Al contrario, su proyecto adquiere forma por medio de una cuidada estrategia de reconfiguración que requiere de la preexistencia de los Mapas y de las Bibliotecas para establecer a partir de estas nuevas posiciones centrales y coordenadas recurrentes. En este esquema, la relación del chileno con la narrativa de Jorge Luis Borges es un factor relevante. A partir de un lectura crítica y proliferante de la obra del argentino, Bolaño apuesta por la reconfiguración de la cardinalidad propuesta por el autor de Artificios (1944). Así, frente al Sur, tópico recurrente en la obra borgeana, el chileno delinea un Norte en el que insistirá constantemente, brindando a esta coordenada un valor determinante en el sistema cartográfico propuesto por su obra. Con intensidades similares a las que utiliza Borges para describir el Sur en su relato homónimo o en «El evangelio según Marcos», Bolaño configura el Norte como un espacio enrarecido, donde el peligro y la muerte se enseñorean, un sitio en el que quien lo transita se ve imposibilitado para reconocerse a sí mismo, donde los sujetos que lo habitan se ubican en una posición ambigua, entre el canalla y el héroe. Y no obstante el riesgo, un lugar que es preciso recorrer, un espacio que imanta los viajes, un destino recurrente al que los personajes descritos por el chileno acuden en la búsqueda de algo que, por lo general, no es hallado o queda en la ambigüedad.

Este trabajo busca situarse y espejear el espacio en que los Mapas y las Bibliotecas se superponen, donde se sobreimprimen sus registros. Desde ahí propongo una lectura del poema «Los Neochilenos», publicado en Tres $^{2}$, como una suerte de arte poética que sintetiza las propuestas geográficas y textuales del autor. Para ello, se ofrecerá una cartografía de la cartografía bolañeana: una descripción del mapa diseñado por el autor y una propuesta acerca de sus transacciones con los diversos cánones a los que recurre para la configuración de una biblioteca propia, considerando además el papel central que la narrativa borgeana adquiere en la escritura de Bolaño. Sobre este mapa textual se articulará un diálogo entre el mencionado poema y la posterior producción narrativa

Originalmente publicado por editorial Acantilado en 2007. No obstante, ante la dificultad para acceder a dicho tomo, se trabajará con una edición digitalizada obtenida desde http:/ / biblioteca. dg2.com. Todas las citas corresponden a esa versión. 
de Roberto Bolaño, interacción rizomática que busca discutir la posición central de la narrativa de Bolaño como registro que contiene los indicios para la comprensión de su obra y su política, argumentando que ya en su poesía, precisamente en «Los Neochilenos», el poeta estableció los trazados que posteriormente le permitieron articular sus propios espacios de desplazamiento.

La lectura de dicho poema se justifica a partir de la firma que cierra la obra, «Blanes, 1993». Las ideas propuestas en aquella temprana fecha hacen posible afirmar que el trazado descrito por estos «nuevos patriotas» (53), un viaje hacia «el norte que imanta los sueños» (47), constituye el atisbo del mapa bolañeano que adquirirá coherencia en su producción narrativa, particularmente tras la publicación de Los detectives salvajes (1998). De esta forma, el viaje de Pancho Ferri junto a sus compañeros, en el que recorrerán espacios marginales e invisibles, pueblos ruinosos y fantasmales habitados por sujetos crápulas «[...] encaprichados con / el fist-fucking y el / feet-fucking [...]» (51), deviene el ensayo de un mapa desbordado y de fronteras discontinuas, una cartografía que excede la política de las fronteras nacionales para proponer un plano de desplazamientos en el que se inscribe una comunidad hispanohablante que se reconocería a sí misma por medio de la literatura.

\section{Complicidades entre el mapa y la biblioteca: el canon como agencia territorial}

Quiero iniciar con una afirmación que tendrá una posición central a lo largo de este ensayo: los cánones son discursos geográficos. Estos no son fabricados en un espacio abstracto y transparente de pura dignidad estética, bibliotecas congeladas que reguardan sus legados, sino al contrario, aparecen y desaparecen a través de sus diálogos con un discurso de poder que los reclama y con el que se relacionan en complicidad: el Mapa. Cánones, bibliotecas, archivos: instituciones culturales que se sitúan en un espacio que los condiciona y con el que cooperan: son occidentales, son latinoamericanos, son chilenos, mexicanos o españoles. Múltiples corpus en disputa y en complicidad, cánones que compiten los unos contra los otros en la reyerta por la legitimidad y la supervivencia, siempre sobre un único campo de batalla: el Mapa sobre el que circulan. 
Considerar que los cánones literarios se inscriben en un espacio geográfico lleva a pensar que entre sus efectos está, en un trabajo mancomunado junto a otras agencias, el fortalecer las fronteras y afianzar y legitimar los relatos mediante los que se reconocen las comunidades que transitan en su interior. Su aparente transparencia estética, esa función que Harold Bloom (2006) defiende al afirmar que éstos existen para «[...] que los leas tú y los desconocidos, de manera que tú y aquellos a quienes nunca conocerás podáis encontraros con el verdadero poder y autoridad estéticos» (47), se fisura en el momento en el que nos percatamos de que éstos se inscriben, necesariamente, sobre una organización territorial a la que legitiman y con la que se legitiman.

Para justificar lo anterior, es preciso destacar que las comunidades que se inscriben y determinan a partir de un espacio geográfico (no sólo Estados y Naciones, sino también espacios más amplios como las alianzas políticas internacionales, o imaginarios como Occidente y Oriente, Norte y Sur, etcétera), requieren de un canon literario que permita, junto a otras instituciones, establecer alianzas y tradiciones entre sus miembros. Desde la llamada «teoría gastronómica» ${ }^{3}$, Anthony Smith (2000) repara en ello al sostener que las naciones son leídas como piezas de ingeniería social, artefactos producto del ensamblaje de una rica variedad de fuentes culturales, una acumulación de ingredientes dispuestos para el proceso de autodeterminación de la nación a partir de las representaciones que ésta realiza de sí misma: historia, imagen nacional y literatura canónica (Smith 186-188). De forma similar, Miguel Metzeltin (2001) afirma que la trama narrativa que permite la configuración del Estado-nación requiere, entre otros ritos, la toma de posesión de un espacio, la territorialización», junto a un ejercicio de representación estética de una identidad nacional en la que los sujetos podrían llegar a reconocer los valores que les

Lo que sugiere la «teoría gastronómica» es que lo ensamblado en la nación son «ingredientes» que buscan proponer una imagen de lo que en ésta se contiene. Escribe Smith (2000): «En este siglo, el símbolo de lo inglés es el ploughman's lunch. Sus ingredientes (pan, queso y pickles) pueden ser venerables, pero no son una peculiaridad de lo inglés, y su yuxtaposición fue una invención cultural de los sesenta [...] los nacionalistas y sus seguidores han juntado los diversos ingredientes de la nación -historia, símbolos, mitos, lenguas- de un modo muy semejante a aquel que los dueños de los pubs juntan los del ploughman's lunch. Al hacerlo, es frecuente que seleccionen elementos de orígenes diversos, especialmente si, como tan a menudo sucede en las sociedades modernas, las fronteras del Estado incluyen varias comunidades étnicas» (186-187).

4 Junto a los mencionados elementos, el autor también agrega la necesidad de una historización de la comunidad, la estandarización e historización de una lengua nacional, la institucionalización, y la medialización y globalización (Metzeltin 242). 
permiten articularse como una colectividad con vínculos indestructibles: una «literatura nacional» ${ }^{4}(242)$.

Benedict Anderson (1993) sostuvo que las naciones son «comunidades imaginadas» debido a que «[...] aún los miembros de la nación más pequeña no conocerán jamás a la mayoría de sus compatriotas [...] pero en la mente de cada uno vive la imagen de su comunión» (23). Frente a ello ¿No es válido sospechar del canon como una institución que permite la articulación de un patrimonio en el que la comunidad se encuentre a sí misma, idealizada, reformulada, reconstruida por medio de la escritura? ¿No es el canon acaso una institución que permite mantener viva la imagen de la comunidad? Pues, a la luz de lo antes expuesto, es válido pensar que sí. En consecuencia, las palabras de Harold Bloom (2004), «[...] todos los cánones, incluyendo los contracánones, son elitistas» (47), son legibles bajo una nueva luz.

Si, como sostiene Bourdieu (2002), las jerarquías y posiciones centrales al interior de los campos culturales son consecuencia de un discurso de poder emitido por una «[...] pluralidad de potencias sociales [que] en virtud de su poder político o económico o de las garantías institucionales de que disponen, están en condiciones de imponer sus normas culturales a una fracción más o menos amplia del campo intelectual [...]» (las cursivas son mías; 31), la deconstrucción de los cánones constituye entonces un ataque a las élites y sus Archivos, que permite cuestionar no sólo los espacios «afuera» y «dentro» que éstos determinan, es decir lo canónico y lo no-canónico, sino además cuestionar el espacio geográfico sobre los que los cánones se inscriben, es decir, el «afuera» $\mathrm{y}$ «dentro» de las fronteras geopolíticas.

Un punto importante en este debate es la literatura de Roberto Bolaño. No obstante su posición central en la actualidad, un desplazamiento desde el margen hacia el centro que ejemplifica claramente la movilidad y artificialidad de los corpus, no se puede soslayar que la suya es una escritura profunda y problemáticamente influenciada por los cánones que le anteceden y con los que se relaciona. Un primer punto de conflicto en esta tensión tendría que ver con su lectura personal de la tradición, una revuelta de las lecturas que buscaría intencionadamente oponerse a las obras precedentes con la intención de entrar en una disputa mediante la que Bolaño evalúa su propia voz: 
A veces se enfrentaba a Cortázar, al cual una vez llegó a vencer por nocaut en el décimo round; otras, se abalanzaba contra el dúo de luchadores técnicos formado por Vargas Llosa y Fuentes; y, cuando se sentía particularmente fuerte o colérico o nostálgico, se permitía enfrentar al campeón mundial de los pesos pesados, el destripador de Aracataca, el rudo García Márquez, su némesis, su enemigo mortal y, aunque sorprenda a muchos, su único dios junto a ese dios todavía mayor, Borges. (Volpi 193)

La metáfora pugilística es relevante ya que nos permite vislumbrar una batalla constante del autor contra el enquistamiento del boom y posterior congelamiento postal de la literatura latinoamericana. Si «[...] la literatura es o puede ser el instrumento de conocimiento de una cierta verdad del mundo» (Rojo 205), aquel enquistamiento atentaría contra el reconocimiento de la diversidad de variables políticas y estéticas que circulan en el continente, relegadas todas a una posición de minusvalía frente al exotismo macondiano. La batalla de Bolaño debe ser interpretada desde el reconocimiento de la diferencia, una apuesta política por la heterogeneidad que se disputa en un amplísimo ring: América. El campo de la lucha bolañeana se ubica en un constante desplazamiento que al mismo tiempo recusa y pone en diálogo las fronteras nacionales: el espacio geográfico se extiende en la configuración de un mapa difuso, sin fronteras, y en la articulación de una biblioteca desterritorializada ${ }^{5}$, en proliferación de lecturas cruzadas.

En este punto, es preciso considerar las ideas propuestas por Felipe Ríos Baeza en Roberto Bolaño: una narrativa al margen. Desestabilizaciones en el canon y la cultura (2013), quien plantea una gran cantidad de ejemplos que argumentan a favor de esta tensión ${ }^{6}$. De sus propuestas, que oscilan entre la parodia y la admiración, me interesa por sobre todo su lectura de la figura del artista-torturador en La literatura nazi en América (1993)

\footnotetext{
Utilizo en concepto de desterritorialización propuesto por Delueze y Guattari (2006), quienes al explicar los desplazamientos propios del rizoma, sostienen que «[...] las multiplicidades se definen por el afuera: por la línea abstracta, línea de fuga o de desterritorialización según la cual cambian de naturaleza al conectarse con otras» (la cursiva es mía; 14). De esta forma, un trayecto de desterritorialización no es de salida de un sistema hacia un espacio de intemperie y aniquilación, sino que al contrario, es la línea fertilizadora, productiva, que permite la simbiosis entre sistemas diversos para provocar la proliferación de multiplicidades.

6 Me refiero particularmente a la primera parte de dicho estudio: «Tensiones en el canon: crítica y parodia de las estrategias institucionales» (29-117).
} 
y Estrella distante (1996), un diálogo entre el artista de vanguardia y el régimen de facto sobre el que se concluye que evidenciaría como «[...] el canon requiere de un organismo especial que aplique la fuerza frente a la disidencia, del mismo modo que la institución estatal requiere de la violencia organizada para controlar a la oposición» (Ríos Baeza 49). Un caso de cooperación entre los proyectos creadores y el poder, un vínculo indisoluble entre las élites mencionadas por Bourdieu y las estrategias de violencia implícitas o explícitas que permiten llevar a cabo la articulación de corpus canónicos operativos a la hora de construir los relatos mediante los que dichas élites aseguran su posición. $\mathrm{O}$ como se narra en «Los Neochilenos» sobre el abogado Vivanco, quien «[...] Preguntó qué mierdas queríamos decir / con esa huevada de los Neochilenos. / Nuevos patriotas, dijo Pancho [...] Y el abogado Vivanco / volvió a enfundar la pistola» (Bolaño 53). En aquella pistola se inscribe el indicio de la resistencia de las instituciones culturales frente a los discursos que disputan un espacio legítimo de circulación, la violencia que se opone a lo nuevo, la estrategia que preserva las fronteras que delimitan los espacios que restringen el acceso a las posiciones de poder.

Al revelar y atacar los centros de poder, sean éstos escriturales y/o geográficos, los personajes de Bolaño llevan a cabo un proceso de descentramientoqueles permite desafiar «[...] losimpulsos minorizadores y periferializadores de las culturas dominantes» (Brah 241). Redefiniendo el mapa, la frontera se recusa como agencia que determina a los sujetos que la transitan y / o que son determinados a partir de su cercanía o lejanía a ésta por medio de sus posiciones de centralidad o marginalidad. Más que una línea continua que busque clausurar un espacio determinado, el margen y la frontera son, al contrario, líneas discontinuas similares a las que en Los detectives salvajes (1998) registra Juan García Madero el día 15 de febrero, la última entrada de su diario:

¿Qué hay detrás de la ventana?

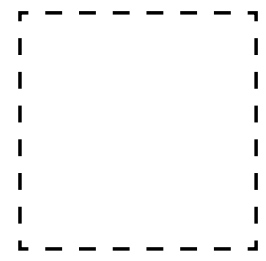

(609) 
En los dibujos anteriores del poeta, los correspondientes a los días 13 y 14 de febrero (608-609), la línea que sugiere la ventana es continua. Por medio de ésta se clausura un espacio, se demarcan los límites entre zonas interiores y exteriores, lo que dota a ambos diagramas de una coherencia que se inscribe en la delimitación de las fronteras como agencias de orden. De aquel orden, de aquella lógica, se desprende que la pregunta «¿Qué hay detrás de la ventana?» posea una respuesta posible: una estrella y una sábana extendida. Es decir, la frontera constituye un principio ordenador que se caracteriza por el binarismo y que se actualiza en los primeros dibujos de García Madero por medio de la demarcación de zonas adentro/afuera que se corresponden con sus consecuentes preguntas / respuestas. Sin embargo, el dibujo aquí citado se diferencia de los anteriores por la discontinuidad, por la línea cuyas zonas en blanco, sus interrupciones, devienen los puntos de entrada y salida que permiten los intercambios constantes entre aquello que está contenido al interior de la figura y eso que se ubica en su exterior. Desarticulada de esta forma la frontera, la pregunta «¿Qué hay detrás de la ventana?» ya no puede ser contestada debido a que se ha fracturado la agencia de orden que dota de coherencia e inteligibilidad al espacio antes clausurado.

De lo anterior se desprende la posibilidad de establecer confluencias de sentido entre la ventana y el mapa en la medida en que ambas instancias constituirían agencias que determinarían posiciones de privilegio a la hora de llevar a cabo procesos de reconocimiento del espacio circundante: a través de la ventana observo para reconocer el paisaje que me rodea, $\mathrm{mi}$ afuera, mi exterior; en el mapa, me ubico y ubico mi espacio, lo reconozco a partir de su representación gráfica. Ambas instancias, mapa y ventana, no obstante, parcelan mi mirada, limitan mi perspectiva: me permiten ver solo eso que está contenido al interior de sus márgenes, una fracción parcelada de la realidad. Al contrario, en su apertura, en la discontinuidad de sus límites, la mirada se enriquece. Así, aquel diagrama ya no puede ser leído como una representación literal del objeto ventana, sino como una figura confluyente o acaso una metonimia del mapa. De esta forma, en sus límites discontinuos subyace una fórmula acerca de los límites de los espacios, la propuesta de una cartografía que reivindica la apertura, el movimiento y la incerteza que subyace bajo los principios ordenadores de la frontera como estrategia que regula el mapa político. 


\section{Borges contra Bolaño: el asalto a la biblioteca del sur}

Como sostiene Carolina Ramírez (2008), a propósito del texto «Biografías mínimas/ínfimas y el equívoco del mal» (2000) de Celina Manzoni, ciertas escrituras de Borges y Bolaño coinciden en la exploración de una memoria a la que se introduce un agente traumático: la «recuperación de lo infame» (45). Por medio del personaje monstruoso, la biografía apócrifa de lo imposible, Jorge Luis Borges abre en la Historia universal de la infamia (1935) una senda que luego Roberto Bolaño transitará, de forma nítida y evidente, en $\mathrm{La}$ literatura nazi en América (1996). Pero los rastros de esta influencia son aún mayores y se vinculan con la articulación del mapa que el chileno delineará en su narrativa y cuyos antecedentes se hallan, de acuerdo a la hipótesis de este trabajo, en el poema «Los Neochilenos». Sutilmente, Bolaño recorre el mapa borgeano y se apropia de éste; mediante aquel asalto, el chileno desdibuja las fronteras y permite así la circulación de los elementos interiores y exteriores que estas delimitan.

En los relatos «El sur» (1953) y «El evangelio según Marcos» (1970), centrales en la articulación del universo borgeano, el argentino delinea un espacio idealizado del sur geográfico como lugar en el que se extiende una ética que es descrita con características míticas: sujetos telúricos, canallas de cuchillo, una ética hostil al porteño aburguesado que atraviesa hacia el «otro lado de Rivadavia» (Borges, «El Sur» 225). «En el campo desaforado, a veces no había otra cosa que un toro», se narra en el más antiguo de estos relatos, y se agrega que: «La soledad era perfecta y tal vez hostil, y Dahlmann pudo sospechar que viajaba al pasado y no sólo al Sur» (226). Acudir al Sur parece ser un desplazamiento geográfico y temporal hacia un locus imbuido por el fantasma de Martín Fierro (1872), omnipresente en la obra borgeana. De forma similar, en el otro de estos relatos, los habitantes del Sur son descritos según la perspectiva de un narrador cómplice a la experiencia del indolente Baltasar Espinosa: sujetos toscos, ignorantes, infantiles:

Una noche, Espinosa les preguntó si la gente guardaba algún recuerdo de los malones, cuando la comandancia estaba en Junín. Le dijeron que sí, pero lo mismo hubieran contestado ante una pregunta sobre la ejecución de Carlos Primero. Espinosa recordó que su padre solía decir que casi todos los 
casos de longevidad que se dan en el campo son casos de mala memoria o de un concepto vago de las fechas. Los gauchos suelen ignorar por igual el año en que nacieron y el nombre de quien los engendró. (Borges, «El evangelio» 425)

En aquel Sur, ambos personajes, Dahlmann y Espinosa, se enfrentan a la muerte invocada por medio del desajuste que implica la lectura de los códigos de esa tierra ignota a través de los valores del sujeto burgués. El primero, transformado en un pampeano a medias, caerá en un enfrentamiento a cuchillo tras salir a la llanura; el otro, devenido Cristo crucificado bajo un cielo estrellado que se despeja luego del diluvio, espera indolente su propia muerte. En ambos el espacio es el testigo silente de la caída.

Este diseño del espacio fue actualizado por Bolaño en el relato «El gaucho insufrible» (2003). El viaje del abogado Héctor Pereda al Sur borgeano permitirá la actualización del personaje, quien de ser un «tierno padre de familia y un abogado intachable» («El gaucho»15), devendrá pampeano y Cristo que, tras su regreso a Buenos Aires, extrañado de la otrora ciudad tan suya, se pregunta:

¿Qué hago [...] me quedo en Buenos Aires y me convierto en un campeón de la justicia, o me vuelvo a la pampa, de la que nada sé, y procuro hacer algo de provecho [...] tal vez con los conejos, tal vez con la gente, esos pobres gauchos que me aceptan y me sufren sin protestar? Las sombras de la ciudad no le ofrecieron ninguna respuesta. Calladas, como siempre, se quejó Pereda. Pero con las primeras luces del día decidió volver. (51)

Lo cierto es que la zambullida de Bolaño en la obra de Borges es directa y sin empachos ni disimulos. Entre la parodia y la admiración, el chileno establece con la obra del argentino una dinámica de intertextualidad proliferante que, como sostiene Gustavo Faverón-Patriau (2008), le permite al autor «[...] transitar por la letras argentinas sin cargar el peso de la tradición sobre sus hombros [...] A través de estas referencias, Bolaño produce un tejido de observaciones en apariencia furtivas pero en el fondo coherentes sobre temas cruciales de dicha tradición» (374). A la senda de Borges, Bolaño delinea un mapa que no se agota en la aventura de Pereda, sino que se extiende a través de otro relato en el que 
se problematiza el Sur: «Detectives», publicado en Llamadas telefónicas (1997), narra la detención de un joven Arturo Belano en Concepción, quien en 1973 viaja al Sur, desde México a Chile, para aportar al proceso revolucionario impulsado por el gobierno de la Unidad Popular. Tal como Pereda, tal como antes sucede como Dahlmann y Espinosa, a Belano el Sur lo transforma hasta el punto en que es incapaz de reconocer su propia imagen en un espejo: «[...] él se miró, asomó su cara y se miró, incluso se pasó una mano por el pelo, echándoselo para atrás [...] y luego desvió los ojos, sacó la cara del espejo y se estuvo un rato mirando el suelo [...] Y él entonces me miró a los ojos y me dijo: es otro, compadre, no hay remedio» (Bolaño, Detectives 131).

Mediante su lectura de Borges, Bolaño asedia el canon argentino y latinoamericano, movilizando sus intensidades y transformándolo. Releyendo, el chileno interviene a Borges y así reconfigura una biblioteca que alterará los valores que definen el Sur descrito por el argentino, trastornando así tanto el espacio geográfico como a las comunidades que se inscriben y reconocen en éste. Y como consecuencia de dicha relectura, Bolaño ofrece su propia versión travestida, ambigua, actualizada: el Norte. En otras palabras, mediante el asalto a la biblioteca, Bolaño desdibuja el mapa y sus centros para trazar su propia cartografía. En este mapa, el Norte es un espacio idealizado y hostil en el que quien lo transita se ve imposibilitado de reconocerse a sí mismo y al tiempo que ahí se extiende, donde los sujetos que lo habitan se ubican en una posición ambigua, entre el canalla y el héroe, acaso marginal, a veces enloquecidos debido a la pérdida de las referencias que subyacen bajo el trazado de la frontera/orden. Algunos ejemplos paradigmáticos: desde el D.F. hacia el Norte, se embarcan Ulises Lima y Arturo Belano en la búsqueda de Cesárea Tinajero en Los detectives salvajes; desde Concepción hacia España, el Norte nuevamente, comprende la investigación tras los pasos de Carlos Wieder que realizan Belano y Abel Romero en Estrella distante; México es el destino del chileno Mauricio Silva, el Ojo Silva, tras su exilio, primera parada en un viaje que le llevará a reconocer la violencia que persigue a los «[...] nacidos en Latinoamérica en la década de los cincuenta [...]» (Bolaño, Putas 11); es al Norte, Santa Teresa, el lugar al que se dirigen los críticos que buscan afanosa e infructuosamente al fantasma de Archimboldi en 2666 (2004). Por último, y en 1993, el Norte que «[...] imanta los sueños [...]» (Tres 47) es el destino perseguido por los afiebrados Neochilenos. 


\section{«Qué mierdas queríamos decir con esa huevada de los Neochilenos»}

Aquella insistencia en el Norte me permite sugerir que una estrategia central en la literatura de Roberto Bolaño es la de configurar y reconfigurar constantemente una política del espacio por el que se extiende la comunidad hispanohablante, cuyas coordenadas centrales serán, para el autor, México, España y Chile. Su primera ofensiva será desde la trinchera de la escritura, desde la biblioteca, desarticulando el canon por medio del ataque crítico, la articulación de lecturas cruzadas y la introducción de elementos marginales:

[...] Bolaño irá conformando su particular ética del oficio y permitirá en el ámbito de la literatura, inicialmente ordenada y con criterios jerárquicos [...] la infiltración subrepticia de componentes periféricos que volverán caótica y ambigua la distinción de aquello que previamente estaba en el «interior»y de eso que permanecía en los «márgenes». (Ríos, «Mapas» 241)

Si el canon es un discurso geográfico, como antes se ha explicado, esta interpretación des-jerarquizadora permite sostener una intervención que dialoga de forma directa con su otra ofensiva: la recusación de las políticas del espacio geográfico y las fronteras que lo determinan. Así, Bolaño llevaría a cabo un delineamiento de mapas de tránsitos, de fugas y aperturas, a los que:

[...] vuelve de manera intermitente, adscribiend características concretas y valores personales a cada uno de estos espacios. Los personajes que los habitan circulan por ellos libremente, ocupando lugares centrales o secundarios según la locación. El mapa cognitivo de Bolaño no es el Macondo de García Márquez, territorio utópico, exótico y de límites claramente establecidos, sino la aldea global marcada por viajes y un contraste permanente con lo local. (240)

En otras palabras, la escritura de Bolaño tensiona los cánones y, al hacerlo, fisura los márgenes geográficos sobre los que éstos se asientan. En consecuencia, en Bolaño asistimos a la construcción de un mapa en el que los espacios escriturales y geográficos constantemente son puestos en entredicho y desarticulados por medio de una interpretación de los 
márgenes como punto de intercambio entre los espacios interiores y exteriores.

Tal como sucede en Los detectives salvajes, en cuyas páginas finales Lupe y García Madero recorren un Norte salpicado de hitos mínimos que actúan como coordenadas fantasmales de un espacio ininteligible, la antesala del extravío que cierra la novela, el viaje de los Neochilenos traza una línea que recorre diversos espacios alejados de los centros de poder: «[...] Toco, Quillagua, / Hilaricos, Soledad, Ramaditas / Pintados y Humberstone, / actuando en fiestas vacías / y burdeles reconvertidos / en hospitales de Liliput [...]» (Bolaño, Tres 51), pueblos polvorientos y olvidados, antiguas oficinas salitreras algunos, viejos antros que reivindican por medio de su presencia fantasmal la marginalidad como espacio de subversión. Si la frontera, cada vez más cercana en este tránsito hacia el Norte, tiene la posibilidad de «[...] transformarse imperceptiblemente en una liminaridad contenciosa interna, que proporciona un sitio desde el que hablar de, y como, la minoría, el exiliado, el marginal y el emergente» (Bhabha 185), al instalar a sus personajes sobre el margen/frontera (escritural y/o territorial), Bolaño dinamiza los flujos congelados por el discurso cohesionador de la nación o la colectividad: «[...] los límites / son tenues, los límites / son relativos: gráfilas / de una realidad acuñada / en el vacío [...]» (50), dice Pancho Ferri a los Neochilenos tras narrar la travesía del porteño Jetachancho, migrante chileno radicado en Barcelona que llena sus bolsillos por medio del tráfico de drogas, acaso refiriendo la relatividad de los límites geográficos que subvierten en su propia condición de migrantes que dinamizan y subvierten el mapa.

No obstante abierta, la frontera se describe como un espacio riesgoso. De ahí que al salir de Arica hacia el Norte, se narre que: «[...] cruzamos la frontera / de la República. / Por nuestros semblantes / hubiérase dicho que cruzábamos / la frontera de la Razón» (54). Mediante la vinculación gráfica que se sugiere en el uso de las mayúsculas y que deviene

Sobre aquel viaje, que quedará inconcluso para el lector, se menciona que el día 10 de febrero se visita Cucurpe, Tuape, Meresichic, Opodepe; el día siguiente, Carbó, El Oasis, Félix Gómez, El Cuatro, Trincheras, La Ciénaga; finalmente, el día 12 de febrero, Bamuri, Pitiquito, Caborca, San Juan, Las Maravillas, Las Calenturas (Bolaño, Los detectives 608). Sobre cuál es el pueblo en el que se realizan los comentados dibujos nada se dice, añadiendo más misterio al misterio de aquel Norte imposible en el que transitan los personajes tras la muerte de Cesárea Tinajero. 
confluencia de sentidos, República y Razón son instancias puestas en una situación de equivalencia que, considero, se emparentan a partir de su posición de poder y orden. Definida la República como un espacio limitado por unas fronteras que, como antes sugerí, pueden ser leídas como un principio ordenador que se actualiza por medio de sistemas binarios (adentro/afuera), al abandonar esta República los Neochilenos transitan desde la Razón hacia un espacio de ( $\sin$ )Razón: el imperio de una incoherencia en el que el sujeto se extravía al no hallar los principios que determinan sus vínculos con el mapa y el espacio que éste representa. De ahí que «[...] Pancho Misterio, no salía / de la fiebre» (55), signo del delirio en el espacio abierto que se refuerza por medio de la presencia de lo desconocido: Pancho Ferri ahora es Pancho Misterio, sujeto en cuyo nombre se inscribe lo inexplorado, lo no visto, lo oculto tras la pregunta de García Madero y su ventana fisurada.

¿Quiénes son los Neochilenos? Sabemos sobre su viaje, que es hacia el Norte; sabemos de su extravío en la fiebre que es el delirio de los espacios abiertos; sabemos también de su marginalidad, de su estética que es también su ética, una sobre el dinamismo a través de la frontera abierta. Pero al intentar aclarar qué es lo representado por medio de estas figuras, creo preciso recordar que, como otros críticos han sostenido, la obra de Bolaño deambula en los márgenes literarios y culturales de la década de 1960 para constituirse como un homenaje a su generación, opinión que es refrendada por el mismo autor:

Todo lo que he escrito es una carta de amor o de despedida a mi propia generación, los que nacimos en la década del cincuenta y los que escogimos en un momento dado el ejercicio de la milicia, en este caso sería más correcto decir militancia, y entregamos lo poco que teníamos, lo mucho que teníamos que era nuestra juventud, a una causa que creíamos la más generosa de las causas del mundo, y que en cierta forma lo es, pero en realidad no lo era. (Ctdo. Candia 12)

Lo que Bolaño refiere es la seguidilla de inmolados, tanto los asesinados por los regímenes de derecha como quienes se sacrificaron en las obsesiones revolucionarias, que se arrojaron a los distintos proyectos emancipatorios de las décadas de 1960-70, un suceso narrado por Auxilio Lacouture en Amuleto (1999), quien describe, en un sentido tono elegiaco, el destino de los proyectos revolucionarios en América Latina: 
Y los oí cantar, los oigo cantar todavía, ahora que ya no estoy en el valle, muy bajito [...] a los niños más lindos de Latinoamérica, a los niños mal alimentados y a los bien alimentados y a los que no tuvieron nada, qué canto más bonito es el que sale de sus labios, que bonitos que eran ellos, qué belleza, aunque estuvieran marchando hombro con hombro hasta la muerte [...] Lo único que pude hacer fue ponerme de pie, temblorosa, y escuchar hasta el último suspiro de su canto [...] porque aunque a ellos se los tragó el abismo el canto siguió en el aire del valle [...] Así pues los muchachos fantasmas cruzaron el valle y se despeñaron en el abismo. Un tránsito breve. (153)

Es relevante que en el poema que nos preocupa se sostenga que los Neochilenos son «sobrevivientes [...] latinoamericanos con suerte» (62), oponiendo esa supervivencia a la muerte narrada en Amuleto, lo que me lleva a pensar que éstos afortunados chilenos en tránsito, bien podrían ser la imagen fantasmal del remanente de los latinoamericanos inmolados. De esta forma, el viaje deviene el eco de la revolución inconclusa, en el devenir diaspórico como gesto a una política pendiente que, inconclusa en las décadas de 1960-70, se ajusta a la subversión del mapa como estrategia que explora un nuevo espacio de emancipación.

\section{A modo de coda: el viaje y la búsqueda de lo nuevo}

Nuevos patriotas, revolucionarios, cartógrafos, locos, marginales. Son muchas las cosas que a estas alturas podríamos decir sobre los Neochilenos en esta coda que no es una conclusión. ¡Qué lejos estamos de concluir algo! Si mi intención primera ha sido la de argumentar a favor de la incidencia de la poesía de Roberto Bolaño como atisbo del diseño del mapa, ya no narrativo ni poético, sino un mapa bolañeano trasversal, queda aún una gran tarea pendiente, un análisis pormenorizado, puntilloso y comparativo entre sus dos registros. Pero algo hemos avanzado. Si consideramos que el trabajo poético de Bolaño es parte de «[...] la prehistoria del narrador» (Ayala 99), no podemos evitar darnos de frente con el hecho insoslayable de que parte importante del material escrito por Roberto antes de Bolaño estará contenido en su producción poética. Sin embargo, Matías Ayala erraría al afirmar que el chileno deja de escribir poesía para «[...] escribir sobre poetas, para ficcionalizar su 
propia vida azarosa y su fracasada carrera poética [...]» (100), ya que, como se ha sostenido a lo largo de este trabajo, no es solo el indicio de los futuros personajes novelescos lo que encontramos en la poesía de Bolaño, sino que también un diseño de espacios con profundas raíces políticas que recorre los mapas y los cánones con los que su producción escritural, toda ésta, se relaciona.

En una entrevista publicada en Primera Linea (2000), el autor refiere un dato que creo imprescindible a la hora de entender los vínculos entre lo que Ayala llama su «prehistoria»y su «historia». «¿De dónde viene usted?», pregunta la periodista, ante lo que Bolaño sostiene:

Creo que vengo de la poesía [...] Yo básicamente soy poeta. Empecé como poeta. Casi siempre he creído, y aún sigo creyéndolo, que escribir prosa es un mal gusto bestial [...] Es mucho más difícil la poesía. Las escenografías que te proporciona la poesía son de una pureza y de una desolación muy grande. Cuando juntas pureza y desolación el escenario se agranda automáticamente hasta el infinito y lo lógico es que tú también desaparezcas en ese escenario $y$, sin embargo, no desapareces. Te haces infinitamente más pequeño, pero no despareces. (Jösch, párr. 14-15; las cursivas son mías)

Es interesante ver que aquel oficio de poeta es presentado como algo sostenido en el tiempo: vengo de la poesía, soy poeta. De ahí que no sea descabellado pensar que la poesía de Bolaño no es parte de una "prehistoria», sino al contrario, es un registro paralelo, acaso menos visible, pero análogo a la prosa que significó el reconocimiento para el autor. Con respecto a ello, es relevante destacar la insistencia, en aquellas palabras, en aspectos como el escenario, el infinito y el sujeto: creo que ahí se contiene, refrendada por Bolaño, la hipótesis del diseño de un mapa (la escenografía) que se expande por medio de los tránsitos y la apertura (se agranda hasta el infinito), y en la que transitan sujetos marginales y enloquecidos, "para siempre / gobernados / por el azar», apenas capaces de comprender la inmensidad de aquella cartografía sin hitos, rutas ni fronteras. 


\section{Referencias bibliográficas}

Anderson, Benedict. Comunidades imaginadas. México D.F.: Fondo de Cultura Económica, 1993.

Ayala, Matías. "Notas sobre la poesía de Roberto Bolaño". Bolaño Salvaje. Ed. Paz-Soldán, Edmundo y Gustavo Faverón-Patriau. Barcelona, Editorial Andalaya, 2008. pp. 91-101.

Bhabha, Homi. El lugar de la cultura. 1994. Buenos Aires, Manantial, 2002.

Bloom, Harold. El canon occidental: la escuela y los libros de todas las épocas. 1997 Barcelona: Anagrama, 2004.

Bolaño, Roberto. 2666. 2004. Barcelona, Anagrama, 2014.

__. Amuleto. Barcelona, Anagrama, 1999.

_... El gaucho insufrible. 2003. Barcelona, Anagrama, 2010.

__. Entre paréntesis. Barcelona, Anagrama, 2004.

__. Estrella distante. 1996. Barcelona, Anagrama, 2013.

_.. La literatura nazi en América. 1996. Barcelona, Anagrama, 2013.

__. Llamadas telefónicas. 1997. Barcelona, Anagrama, 2013.

__. Los detectives salvajes. 1998. Barcelona, Anagrama, 2010.

_.. Putas Asesinas. Barcelona, Editorial Anagrama S.A., 2001.

__. "Si viviera en Chile, nadie me perdonaría esta novela". Entrevista por Melanie Jösch www.letrass5.cl. 27 de diciembre de 2015. En línea.

_.. Tres. Barcelona, Acantilado, 2007.

Borges, Jorge Luis. Cuentos completos. 2012. Buenos Aires, DeBolsillo, 2015.

Bourdieu, Pierre. Campo intelectual, campo de poder. Buenos Aires, Montressor, 2002.

Brah, Avtar. Cartografías de la diáspora. Identidades en cuestión. 1996. Madrid, Traficantes de Sueños, 2011.

Candia-Cáceres, Alexis. "¿Cómo construir puentes invisibles? Tejidos transparentes y lineas de fuga en la literatura de Roberto Bolaño". Anales de literatura chilena, no. 21, 2014, pp. 179-198. 
Deleuze, Gilles y Félix Guattari. Mil mesetas: capitalismo y esquizofrenia. 1980. Valencia: Pre-Textos, 2002.

Feverón-Patriau, Gustavo. "El rehacedor: 'El gaucho insufrible' y el ingreso de Bolaño en la tradición argentina". Bolaño Salvaje. Ed. Paz-Soldán, Edmundo y Gustavo Faverón-Patriau. Barcelona: Candaya, 2008, pp. 371-415.

Metzeltin, Miguel. "La construcción discursiva de la República de Chile". Boletín de Filología, Tomo XLVI, no. 1, 2001, pp. 239-253.

Paz-Soldán, Edmundo y Gustavo Faverón-Patriau. Bolaño Salvaje. Barcelona, Editorial Candaya, 2008.

Ramírez, Carolina. "Trauma, memoria y olvido en un espacio ficcional. Una lectura a Estrella distante". Atenea, no. 497, 2008, pp. 37-50.

Ríos Baeza, Felipe. Roberto Bolaño: una narrativa en el margen. Desestabilizaciones en el canon y la cultura. Valencia: Tirant Humanidades, 2013.

Ríos, Valeria de los. "Mapas y fotografías en la obra de Roberto Bolaño". Bolaño Salvaje. Ed. Paz-Soldán, Edmundo y Gustavo FaverónPatriau. Barcelona, Editorial Candaya, 2008, pp. 237-258.

Rojo, Grínor. Globalización e identidades nacionales, postnacionales... ¿De qué estamos hablando? Santiago de Chile, LOM, 2006.

Soberón, Fabián. "Pierre Menard, autor de Bolaño". Espéculo: Revista de estudios literarios, no. 33, 2006.

Smith, Anthony. "¿Gastronomía o geología? El rol del nacionalismo en la reconstrucción de las naciones". La invención de la nación. Buenos Aires, Ediciones Manantial, 2000, pp. 185-209.

Volpi, Jorge. "Bolaño, epidemia". Bolaño Salvaje. Ed. Paz-Soldán, Edmundo y Gustavo Faverón-Patriau. Barcelona, Candaya, 2008, pp. 191-210. 
